\title{
IMPLICAÇÕES DAS INTOXICAÇÕES EXÓGENAS POR AGROTÓXICOS À SAÚDE DO TRABALHADOR: UMA REVISÃO INTEGRATIVA
}

\author{
IMPLICATIONS OF EXOGENOUS POISONING BY PESTICIDES TO WORKERS' \\ HEALTH: AN INTEGRATIVE REVIEW
}

\author{
Iraneide Nascimento dos Santos ${ }^{1}$ \\ Ivana Santos Ferraz ${ }^{2}$ \\ Layse Kelle Silva Lirio ${ }^{3}$ \\ Aline Soares da Silva ${ }^{4}$ \\ Gilmara de Sousa Sotero ${ }^{5}$ \\ Guilherme de Andrade Ruela ${ }^{6}$
}

\begin{abstract}
RESUMO: O presente estudo teve como objetivo analisar as principais evidências científicas sobre as intoxicações associadas à exposição aos agrotóxicos na população de trabalhadores brasileiros. Realizou-se uma revisão integrativa de artigos científicos indexados nas bases de dados LILACS, SCIELO, Google Scholar e PubMed, considerando publicações dos últimos cinco anos, utilizando os seguintes descritores: "Agrochemicals" OR "Pesticides" AND "Poisoning" AND "Brazil". O levantamento da literatura foi realizado no mês de dezembro de 2020. De 19.415 artigos encontrados, II foram incluídos por preencherem os critérios de inclusão, bem como importados para o programa Mendeley ${ }^{\circledR}$, na síntese qualitativa. Os artigos mostram que os agentes químicos, bastante utilizados no combate de pragas, podem acarretar efeitos maléficos à saúde humana. Apesar da subnotificação, os envenenamentos por agrotóxicos causam elevada morbimortalidade, além de não estarem restritos ao trabalho rural. Conclui-se que é necessária a oferta de melhores condições de trabalho para os trabalhadores expostos aos riscos de intoxicação, a criação de legislação para tornar mínimos esses riscos e a promoção da educação em saúde, com a finalidade de conscientizar acerca da relevância das medidas preventivas. Novos estudos sobre essa temática são importantes para a caracterização dos casos registrados das intoxicações por agrotóxicos e dos fatores predisponentes para a ocorrência desses agravos, para que sejam propostas medidas preventivas ou corretivas, bem como evidenciar a relevância da notificação.
\end{abstract}

Palavras-chave: Envenenamento. Agroquímicos. Saúde do Trabalhador. Saúde da População Rural.

\footnotetext{
${ }^{1}$ Enfermeira. Mestra em Patologia, Universidade Federal de Pernambuco. Docente do Instituto Federal de Pernambuco, Ipojuca, Brasil. ORCID: https://orcid.org/oooo-ooor-8449-784o. E-mail: iraneidenascimento@ipojuca.ifpe.edu.br.

${ }^{2}$ Enfermeira. Doutoranda do Programa de Pós-graduação em Enfermagem e Saúde, Universidade Estadual do Sudoeste da Bahia, Jequié, Brasil. ORCID: https://orcid.org/oooo-ooo3-r176-46r5. E-mail: ivanaferraz25@gmail.com.

${ }^{3}$ Enfermeira. Especialista em administração hospitalar e sistemas de serviços, Universidade Federal da Bahia, Salvador, Brasil. ORCID: https://orcid.org/oooo-ooor-7693-1846 E-mail: laysekeller5@hotmail.com.

${ }^{4}$ Enfermeira. Especializanda em Educação Permanente em Enfermagem e Docência em Ciências da Vida, Faculdade de Venda Nova do Imigrante, Guarulhos, São Paulo. ORCID: https://orcid.org/oooo-oooz-72569971 E-mail: aline.soares.81@outlook.com.

5 Enfermeira. Universidade de Fortaleza - Unifor, Fortaleza, Brasil. ORCID: https://orcid.org/oooo-oooz3339-2648 E-mail: gilmarasotero215@gmail.com.

${ }^{6}$ Enfermeiro. Mestre em Saúde Pública, Universidade Federal de Minas Gerais, Belo Horizonte, Brasil. ORCID: https://orcid.org/oooo-ooor-6976-871o E-mail: Guilherme.ruela@ufjf.edu.br.
} 
ABSTRACT: This study aimed to analyze the main scientific evidence on intoxications associated with exposure to pesticides in the population of Brazilian workers. An integrative review of scientific articles indexed in the LILACS, SciELO, Google Scholar and PubMed databases was carried out, considering publications from the last five years, using the following descriptors: "Agrochemicals" OR "Pesticides" AND "Poisoning" AND "Brazil". The literature survey was carried out in December 2020. Of 19,4I5 articles found, II were included because they met the inclusion criteria, as well as imported into the Mendeley ${ }^{\circledR}$ program, in the qualitative synthesis. The articles show that chemical agents, widely used in pest control, can have harmful effects on human health. Despite underreporting, pesticide poisoning causes high morbidity and mortality, in addition to not being restricted to rural work. It is concluded that it is necessary to offer better working conditions for workers exposed to the risks of intoxication, the creation of legislation to minimize these risks and the promotion of health education, in order to raise awareness about the relevance of preventive measures. New studies on this theme are important for the characterization of the registered cases of poisoning by pesticides and the predisposing factors for the occurrence of these diseases, so that preventive or corrective measures are proposed, as well as highlight the relevance of the notification.

Keywords: Poisoning. Agrochemicals. Occupational Health. Rural Health.

\section{INTRODUÇÃO}

O Brasil é o maior consumidor mundial de agroquímicos, a abundância do consumo de agrotóxicos comercializados no país mostrou um grande faturamento líquido na indústria brasileira química, o que está relacionado à falta de legislação, e, desde 2008, utiliza mais de 20 produtos proibidos nos Estados Unidos e União Europeia, fato este que afeta o meio ambiente, a saúde física e mental das pessoas (HENDGES et al., 2019; SILVA et al., 2019).

Ao analisar o modelo de modernização da agricultura brasileira, percebe-se o quanto o Estado vem mantendo e fortalecendo os setores do agronegócio, ancorado na lógica do capitalismo, da produtividade espoliadora do ambiente e da apropriação da vida (ARAÚJO; OLIVEIRA, 20I6).

Dado o exposto, no meio rural, os processos de trabalho, os modos de produção, a situação cultural e as relações sociais estabelecidas estão inseridas em diferentes contextos históricos, político, social e econômico, determinando assim os modos de viver das populações camponesas (MURAKAM et al.,2017).

A combinação desses determinantes gera graus diferenciados de exposição aos agrotóxicos, podendo ocasionar adoecimento. Nesse sentido, as áreas agrícolas são consideradas locais de alto risco em função da utilização dos agrotóxicos no cultivo de alimentos portanto, a população que lá reside ou trabalha torna-se um grupo extremamente vulnerável devido à presença desses agentes que podem ocasionar danos severos à sua saúde (MARTINS et al., 2012), a exemplo das intoxicações (QUEIROZ et al., 2019). 
As intoxicações por agrotóxicos são um grande problema em países em desenvolvimento assim como no Brasil, em virtude do uso excessivo e descontrolado desses produtos químicos (MAGALHÃES; CALDAS, 2019; SILVA; FERREIRA; SILVA et al., 2019). Os casos de envenenamento apresentam como razões os eventos acidental e ambiental, e as tentativas de suicídio (QUEIROZ et al., 2019).

No caso dos acidentes ocupacionais, os trabalhadores agrícolas são um dos grupos ocupacionais que mais se expõem aos agroquímicos durante a manipulação, diluição e preparação das misturas (MAIA et al., 2018), porquanto, o manejo inadequado pode favorecer o surgimento das intoxicações agudas e, a longo prazo, das crônicas (NISHIYAMA, 2003). Ressalta-se que a exposição pode acontecer ao realizar a diluição, a preparação e a aplicação dos agrotóxicos, bem como ao entrar em áreas onde foram aplicados os produtos (NEVES et al., 2020).

Para haver um monitoramento dos registros de notificações, expor a situação das intoxicações por agrotóxicos, balizar os campos de atuação, e reduzir o número desses agravos, as intoxicações por agrotóxicos são de notificação compulsória desde 2004, logo, todos os casos de envenenamento devem ser notificados e registrados através do Sistema de Informação de Agravos de Notificação (SINAN) (BRASIL, 2004). Como também, anualmente são disponibilizados os casos de intoxicações registrados nas publicações do Sistema Nacional de Informações TóxicoFarmacológica (SINITOX), no qual reúne as informações dos 36 Centros de Controle de Intoxicações (CCIs) situados em ig estados e no Distrito Federal (PRESGRAVE; GAMACHO; VILAS BOAS, 2009).

Tendo em vista a atual lógica capitalista e ação de regulação mercantil que induz à substituição do controle estatal pelo mercado (GURGEL et al., 2017), juntamente à comercialização e à expansão do agronegócio, têm implicações no setor da saúde, que demonstra os grandes impactos negativos no Sistema Único de Saúde (SUS), tal como a escassez de recursos financeiros, além de apresentar repercussões na saúde daqueles que estão mais vulneráveis, os laboriosos e residentes em áreas rurais, a saber: envenenamento por agrotóxicos, intoxicações, lesões cerebrais, paralisias, doenças alérgicas, cânceres e outros (SILVA; FERREIRA; SILVA et al., 2019; GURGEL et al., 2017).

Acrescenta-se que, as consequências para a saúde humana e o meio ambiente têm sido negligenciadas, e isto, pode afetar, sobremaneira, a qualidade de vida das gerações futuras em virtude da contaminação dos recursos ambientais (DANTAS et al., 2013). Por isso, este estudo mostra-se relevante, pois fornece embasamento teórico para formuladores de políticas, e profissionais de saúde que lidam diretamente com os casos de intoxicação por agrotóxicos.

O objetivo do presente estudo foi analisar as principais evidências científicas sobre as intoxicações associadas à exposição aos agrotóxicos na população de trabalhadores brasileiros. 


\section{MÉTODO}

Trata-se de uma revisão integrativa da literatura, com o fim de sintetizar os resultados obtidos em pesquisas acerca de um tópico de interesse delimitado na área da saúde, o que permite a identificação das lacunas do conhecimento e efetuado seis etapas (MENDES; SILVEIRA; GALVÃO, 2019).

Às seis etapas deste método são: I) elaboração da pergunta da pesquisa; 2) pesquisa e seleção de estudos primários; 3) extração de dados dos estudos; 4) avaliação crítica dos estudos primários incluídos na revisão; 5) síntese dos resultados da revisão e 6) apresentação do método (WHITTEMORE et al., 2014).

Com base no que foi exposto, a questão norteadora deste estudo foi a seguinte: quais são as evidências científicas sobre as intoxicações notificadas e associadas ao uso de agrotóxicos na população de trabalhadores brasileiros?

Elaborou-se a pergunta a partir da estratégia PICO (METHLEY et al., 2014), sintetizada pelo acrônimo P.I.C.O. Sendo que "P" corresponde à população de interesse composta por trabalhadores adultos da agricultura, da pecuária e aplicadores de agrotóxicos que exercem suas atividades laborais no Brasil; "I" ao fenômeno de interesse, que é a exposição ao uso de agrotóxicos no trabalho; "C"

não se aplica a este estudo; e "O" o desfecho, definido como efeitos na saúde humana, sinais e sintomas de intoxicações agudas, subagudas e crônicas. Foi utilizada a ferramenta PRISMA (Preferred Reporting Items For Systematic Reviews And MetaAnalyses) para orientar a redação da presente revisão.

Essa revisão foi realizada a partir da busca de artigos indexados nas seguintes bases de dados virtuais: Literatura Latino Americana e do Caribe em Ciências da Saúde (LILACS), Scientific Electronic Library Online (SciELO), Google Scholar, e no portal States National Library of Medicine National Institutes of Health (PubMed). Para a busca dos artigos, foram utilizados os descritores em ciências da saúde (DeCS), a partir da Biblioteca Regional de Medicina (Bireme), quais sejam: "Agrochemicals" OR "Pesticides" AND "Poisoning" AND "Brazil". Para encontrar um maior número de estudos de modo a responder à pergunta de pesquisa, não foram incluídos os descritores "Occupational Health" e "Rural Health". O levantamento da literatura foi realizado no mês de dezembro de 2020 .

Os critérios de inclusão foram: artigos nos idiomas, português, inglês e espanhol, publicados nos últimos cinco anos, envolvendo as consequências das intoxicações relacionadas ao uso dos agrotóxicos para a saúde do trabalhador, com resumos disponíveis e acessados na íntegra pelo meio on-line. O recorte temporal justifica-se pelo fato de se buscar a literatura mais recente sobre o assunto. 
Os critérios de exclusão foram estudos acerca do auto envenenamento por agrotóxicos, de análise de exames laboratoriais, artigos de revisão de literatura ou metanálise, monografias, dissertações e teses.

Foram encontradas 19.415 produções nas bases de dados. Ocorreu a etapa de identificação dos artigos, primeiramente, por meio da leitura dos títulos, e em seguida, dos resumos. Daqueles que atenderam aos critérios de inclusão, foi realizada a leitura do artigo na íntegra, dos quais in artigos foram incluídos segundo os critérios de elegibilidade conforme a Figura I.

Figura I - Fluxograma e critérios de seleção e inclusão dos artigos, Recife/PE, Brasil, 202ı.
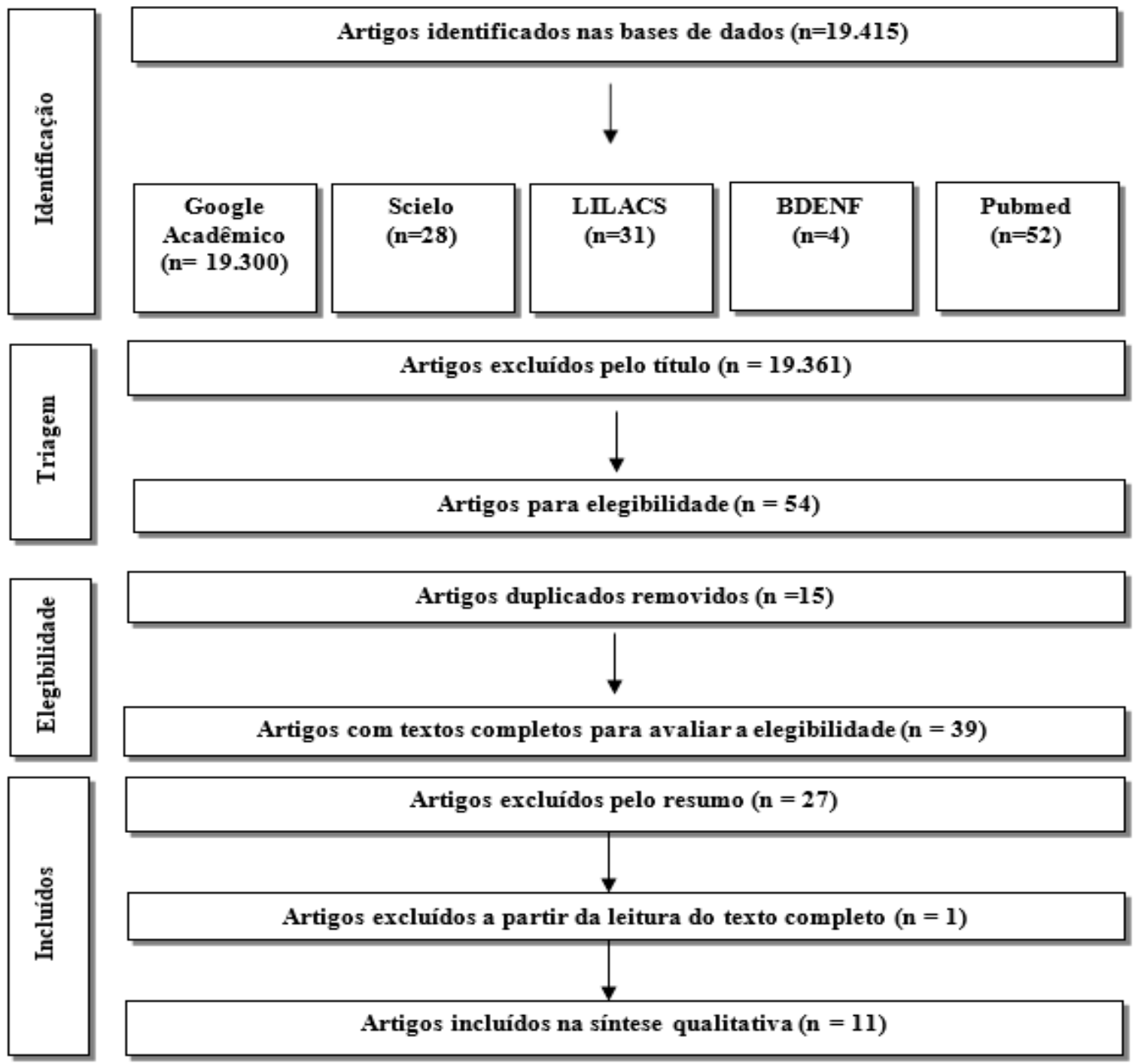

Fonte: Dados da pesquisa.

Os il artigos incluídos na síntese qualitativa foram importados para o programa Mendeley ${ }^{\circledR}$ e foi realizado o direcionamento dos registros referentes ao grupo indicativo de cada base de dados, além disso, foi salvo um arquivo back-up com a busca original, sem qualquer manejo do conteúdo, 
com o propósito de resgatar publicações que possam ter sido excluídas inadvertidamente pelo usuário, como também, para se ter o registro do número de referências encontradas em cada base.

Quanto à apresentação dos resultados da revisão, as informações principais dos estudos foram agrupadas e organizadas em ordem decrescente segundo o nome dos autores e a data da publicação, o título, o nome do periódico, o objetivo e os principais achados de cada artigo Tabela I.

\section{RESULTADOS}

Os resultados do presente estudo encontram-se na Tabela $\mathrm{I}$, na qual apresenta as características encontradas em cada estudo.

Tabela I - Demonstrativo dos artigos que integram a Revisão Integrativa, Recife/PE, Brasil, 202I.

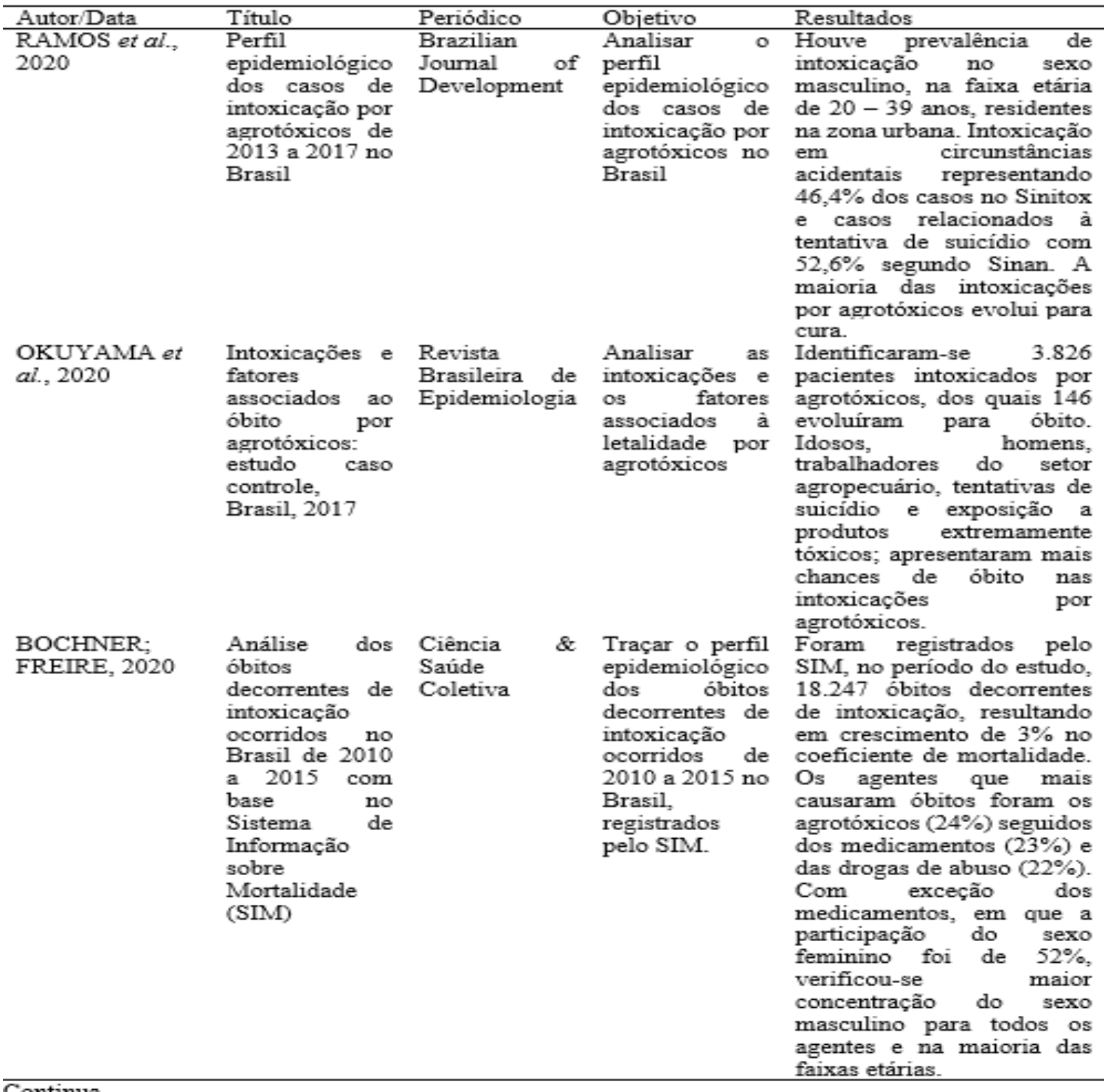




\begin{tabular}{|c|c|c|c|c|}
\hline Autor/Data & Título & Periódico & Objetivo & Resultados \\
\hline $\begin{array}{l}\text { NEVES et al., } \\
2020\end{array}$ & $\begin{array}{l}\text { Intoxicação por } \\
\text { agrotóxicos } \\
\text { agrícolas no } \\
\text { estado de Goiás, } \\
\text { Brasil, de } 2005- \\
2015 \text { : análise } \\
\text { dos registros } \\
\text { nos sistemas } \\
\text { oficiais de } \\
\text { informação }\end{array}$ & $\begin{array}{l}\text { Ciência } \\
\text { Saúde } \\
\text { Coletiva }\end{array}$ & $\begin{array}{l}\text { Caracterizar } \\
\text { intoxicações } \\
\text { por } \\
\text { agrotóxicos } \\
\text { reportadas a } \\
\text { um centro de } \\
\text { informação } \\
\text { toxicológica } \\
\text { de Goiás por } \\
\text { meio de } \\
\text { análise } \\
\text { retrospectiva } \\
\text { no período de } \\
2005 \text { a 2015. }\end{array}$ & $\begin{array}{l}\text { O perfil das intoxicações } \\
\text { apontou para oconência } \\
\text { superior de intoxicações por } \\
\text { tentativa de suicídio e } \\
\text { ocupacional, } \\
\text { predominância de cura dos } \\
\text { intoxicados apesar dos } \\
\text { efeitos crônicos não serem } \\
\text { registrados, sugerindo um } \\
\text { falso diagnóstico de cura. }\end{array}$ \\
\hline $\begin{array}{l}\text { FREITAS et } a l \text {, } \\
2020\end{array}$ & $\begin{array}{l}\text { Caracterização } \\
\text { das notificações } \\
\text { de intoxicações } \\
\text { exógenas por } \\
\text { agrotóxicos no } \\
\text { Rio Grande do } \\
\text { Sul }\end{array}$ & $\begin{array}{l}\text { Epidemiologia } \\
\text { e Serviços de } \\
\text { Saúde }\end{array}$ & $\begin{array}{l}\text { Descrever o } \\
\text { perfil das } \\
\text { notificações } \\
\text { de } \\
\text { intoxicação } \\
\text { exógena por } \\
\text { agrotóxicos } \\
\text { no Rio } \\
\text { Grande do } \\
\text { Sul, Brasil, no } \\
\text { período de } \\
2011 \text { a 2018. }\end{array}$ & $\begin{array}{l}\text { Foram notificados } 3.122 \\
\text { casos suspeitos } \\
\text { intoxicação exógena por } \\
\text { agrotóxicos. O principal } \\
\text { agente tóxico foi o } \\
\text { agrotóxico de uso agrícola. } \\
\text { Pulverização e diluição } \\
\text { revelaram-se as atividades de } \\
\text { maior exposição ao } \\
\text { agrotóxico. A residência foi o } \\
\text { principal local de ocorrência, } \\
\text { e a contaminação acidental } \\
\text { principal motivo da } \\
\text { intoxicação. A maioria das } \\
\text { intoxicações foi do tipo } \\
\text { aguda-única e a avaliação } \\
\text { clínica foi o critério mais } \\
\text { utilizado para o diagnóstico. }\end{array}$ \\
\hline $\begin{array}{l}\text { QUEIROZ et } \\
\text { al., } 2019\end{array}$ & $\begin{array}{ll}\text { Sistema de } & \text { de } \\
\text { Informação de } \\
\text { Agravos de } \\
\text { Notificação e as } \\
\text { intoxicações } \\
\text { humanas por } \\
\text { agrotóxicos no } \\
\text { Brasil }\end{array}$ & $\begin{array}{l}\text { Revista } \\
\text { Brasileira de } \\
\text { Epidemiologia }\end{array}$ & $\begin{array}{l}\text { Analisar as } \\
\text { tendências } \\
\text { das taxas de } \\
\text { incidência da } \\
\text { intoxicação } \\
\text { por } \\
\text { agrotóxicos } \\
\text { nas regiões } \\
\text { brasileiras, de } \\
\text { acordo com } \\
\text { sexo e } \\
\text { circunstância } \\
\text { da intoxicação, } \\
\text { into periodo de } \\
\text { 2001 a 2014. }\end{array}$ & $\begin{array}{l}\text { No Brasil, foram registrados } \\
80.069 \text { casos de intoxicação } \\
\text { nesse perído. Houve um } \\
\text { crescimento linear de } \\
\text { notificações de intoxicação } \\
\text { por agrotóxico, cuja taxa de } \\
\text { tendência de crescimento } \\
\text { encontrada foi de } 0,377 \text { por } \\
100 \text { mil habitantes/ano. As } \\
\text { regiões Sul e Centro-Oeste } \\
\text { apresentam as maiores taxas } \\
\text { de intoxicação. Em relação } \\
\text { ao sexo, não foram } \\
\text { encontradas diferenças } \\
\text { significativas, sendo a } \\
\text { tentativa de suicídio a } \\
\text { circunstância de intoxicação } \\
\text { mais significativa. }\end{array}$ \\
\hline
\end{tabular}

Continua 


\begin{tabular}{|c|c|c|c|c|}
\hline Autor & Título & Periódico & Objetivo & Resultados \\
\hline $\begin{array}{l}\text { MAGALHÄES; } \\
\text { CALDAS, } 2019\end{array}$ & $\begin{array}{l}\text { Exposição e } \\
\text { intoxicação } \\
\text { ocupacional a } \\
\text { produtos } \\
\text { químicos no } \\
\text { Distrito } \\
\text { Federal }\end{array}$ & $\begin{array}{l}\text { Revista Brasileira } \\
\text { de Enfermagem }\end{array}$ & $\begin{array}{l}\text { Descrever } \\
\text { casos de } \\
\text { exposição } \\
\text { ocupacional a } \\
\text { produtos } \\
\text { químicos }\end{array}$ & $\begin{array}{l}\text { Mostram que } 66,7 \% \text { eram } \\
\text { homens, } 55,2 \% \text { tinham até } \\
9 \text { anos de atividade e } 81 \% \\
\text { não usavam equipamento } \\
\text { de proteção individual. } \\
\text { Quase } 60 \% \text { eram } \\
\text { agricultores e agentes de } \\
\text { vigilância ambiental, } \\
\text { expostos a agrotóxicos } \\
(63 \%) \text { dos quais } 40 \% \\
\text { inseticidas } \\
\text { organofosforados. A } \\
\text { maioria (68\%) apresentou } \\
\text { atividade } \\
\text { butirilcolinesterase de } \\
\text { diminuida, principalmente } \\
\text { agricultores ( } 85,9 \%) ; \\
57,3 \% \text { dos trabalhadores } \\
\text { foram considerados } \\
\text { intoxicados, } 61,6 \% \text { por } \\
\text { agrotóxicos e } 37,9 \% \text { por } \\
\text { produtos químicos } \\
\text { industriais. }\end{array}$ \\
\hline $\begin{array}{l}\text { SILVA et al., } \\
2019\end{array}$ & $\begin{array}{l}\text { Exposição } \\
\text { aos } \\
\text { agrotóxicos e } \\
\text { intoxicações } \\
\text { agudas em } \\
\text { região de } \\
\text { intensa } \\
\text { produção } \\
\text { agrícola em } \\
\text { Mato Grosso, } \\
2013\end{array}$ & $\begin{array}{l}\text { Epidemiologia } \\
\text { Serviços e Saúde }\end{array}$ & $\begin{array}{l}\text { Estimar a } \\
\text { prevalência e } \\
\text { os fatores } \\
\text { associados às } \\
\text { intoxicações } \\
\text { agudas por } \\
\text { agrotóxicos em } \\
\text { Mato Grosso, } \\
\text { Brasil. }\end{array}$ & $\begin{array}{l}\text { A taxa de ocorrência de } \\
\text { intoxicação aguda foi de } \\
17 \% \text {; os principais fatores } \\
\text { associados foram residir } \\
\text { na proximidade de } \\
\text { lavouras, possuir até o } \\
\text { ensino médio incompleto e } \\
\text { residir a menos de } 500 \\
\text { metros de lavouras de } \\
\text { milho e de lavouras de } \\
\text { algodão. }\end{array}$ \\
\hline $\begin{array}{l}\text { HENDGES et } \\
\text { al., } 2019\end{array}$ & $\begin{array}{l}\text { Intoxicação } \\
\text { humana por } \\
\text { agrotóxicos } \\
\text { na região sul } \\
\text { do Brasil } \\
\text { entre } 1999 \text { e } \\
2014 \text {. }\end{array}$ & $\begin{array}{l}\text { Joumal of } \\
\text { Environmental } \\
\text { Science and } \\
\text { Health }\end{array}$ & $\begin{array}{l}\text { Avaliar } \\
\text { intoxicações } \\
\text { por agrotóxicos } \\
\text { na região Sul } \\
\text { do Brasil } \\
\text { entre os anos } \\
\text { de } 1999 \text { e } 2014\end{array}$ & $\begin{array}{l}\text { Os resultados } \\
\text { mostraram que os homens } \\
\text { entre } 15 \text { e } 59 \text { anos são mais } \\
\text { afetados; principalmente } \\
\text { na área urbana. A grande } \\
\text { correlação com area } \\
\text { urbana possivelmente } \\
\text { ocorre em função das } \\
\text { correntes de ar trazidas do } \\
\text { campo e, como resultado, a } \\
\text { população tem sido mais } \\
\text { afetada pelo o consumo de } \\
\text { alimentos contaminados. }\end{array}$ \\
\hline
\end{tabular}

Continua 


\begin{tabular}{|c|c|c|c|c|}
\hline $\begin{array}{l}\text { MAIA } e t \\
a l ., 2018\end{array}$ & $\begin{array}{l}\text { Perfil de } \\
\text { intoxicação } \\
\text { dos } \\
\text { agricultores } \\
\text { por } \\
\text { agrotóxicos } \\
\text { em Alagoas }\end{array}$ & Diversitas Journal & $\begin{array}{l}\text { Verificar os } \\
\text { agrotóxicos } \\
\text { notificados que } \\
\text { causam } \\
\text { intoxicação no } \\
\text { Estado de } \\
\text { Alagoas, } \\
\text { comparando } \\
\text { com os } \\
\text { agrotóxicos } \\
\text { mais utilizados } \\
\text { no Brasil. }\end{array}$ & $\begin{array}{l}\text { As variáveis coletadas foram: } \\
\text { idade, sexo do individuo, } \\
\text { municipio, escolaridade, } \\
\text { local da exposição, os } \\
\text { agrotóxicos citados nos } \\
\text { registros de notificações. No } \\
\text { periodo do estudo, foram } \\
\text { verificadas } 248 \text { notificações } \\
\text { pelo uso de agrotóxicos no } \\
\text { estado de Alagoas, que em } \\
\text { sua maioria foi representado } \\
\text { pelos agrotóxicos agrícolas } \\
\text { (74,6\%). Verificou-se que a } \\
\text { exposição ocorre durante a } \\
\text { pulverização principalmente } \\
\text { à classe dos herbicidas, e que } \\
\text { a contaminação ocorre } \\
\text { principalmente no ambiente } \\
\text { de trabalho. }\end{array}$ \\
\hline $\begin{array}{l}\text { SOUZA; } \\
\text { COSTA; } \\
\text { RAMOS; } \\
2016\end{array}$ & $\begin{array}{l}\text { Distribuição } \\
\text { espacial das } \\
\text { intoxicações } \\
\text { exógenas por } \\
\text { agrotóxicos } \\
\text { em } \\
\text { trabalhadores } \\
\text { rurais no } \\
\text { estado da } \\
\text { Bahia-Brasil, } \\
\text { de 2007 a } \\
2011\end{array}$ & Hygeia & $\begin{array}{l}\text { Traçar um } \\
\text { perfil } \\
\text { epidemiológico } \\
\text { e analisar a } \\
\text { distribuição } \\
\text { espacial das } \\
\text { notificações de } \\
\text { intoxicação por } \\
\text { agrotóxicos } \\
\text { nos } \\
\text { trabalhadores } \\
\text { rurais do estado } \\
\text { da Bahia entre } \\
2007 \text { e } 2011 \text {. }\end{array}$ & $\begin{array}{l}\text { Foram notificadas } 696 \\
\text { ocorrências em trabalhadores } \\
\text { de agricultura, pecuária e } \\
\text { serviços relacionados na } \\
\text { Bahia, com concentração dos } \\
\text { casos na região Norte e Oeste } \\
\text { do estado. O público mais } \\
\text { acometido é composto por } \\
\text { homens com idade entre } 20 \text { a } \\
49 \text { anos. Houve uma } \\
\text { tendência para a baixa } \\
\text { escolaridade. O suicídio } \\
\text { liderou as causas de } \\
\text { intoxicações por agrotóxico. } \\
\text { Chama atenção que a } \\
\text { exposição ocorreu tanto no } \\
\text { ambiente de trabalho como } \\
\text { nas residências (40,1\%, } \\
\text { cada), com o quadro clínico } \\
\text { evoluindo para cura sem } \\
\text { sequelas. }\end{array}$ \\
\hline
\end{tabular}

Fonte: Dados da pesquisa

\section{DISCUSSÃO}

De acordo com os artigos pesquisados, este estudo apresenta as principais evidências científicas sobre as intoxicações associadas à exposição aos agrotóxicos na população de trabalhadores brasileiros, apresentando que esses agentes químicos, bastante utilizados no combate de pragas, podem acarretar efeitos maléficos à saúde humana.

Nesse sentido, as intoxicações exógenas são consideradas um grande problema de saúde pública, sobretudo em países que o agronegócio é uma das mais importantes atividades econômicas, a exemplo do Brasil (NEVES; PIGNATI; PIGNATTI et al., 2020), e as intoxicações agudas acometem principalmente os trabalhadores e as populações mais próximas (RAMOS et al., 2020; SILVA; FERREIRA; SILVA et al., 2019). 
Além disso, o paciente, geralmente morador da zona rural, não busca atendimento médico, em virtude do inadequado funcionamento dos sistemas de saúde em determinadas localidades ou pelo fato do sujeito não relacionar a sua sintomatologia ao envenenamento, já que os sinais e sintomas da intoxicação por agroquímicos são como outros problemas de saúde, dificultando a identificação dos casos, gerando subnotificação tanto no Sinan quanto no Sinitox (RAMOS et al., 2020).

Apesar da subnotificação, as intoxicações por agrotóxicos causam elevada morbimortalidade. Isto foi ratificado pelo estudo de Okuyama e colaboradores (2020), no qual foram incluídos 3.826 pacientes intoxicados por agrotóxicos atendidos pelos Centros de Informação e Assistência Toxicológica (CIATox) brasileiros em 2017 e registrados no Datatox, desses, I46 (3,8\%) evoluíram para o óbito. Ainda nesta pesquisa, a maior parte das intoxicações ocorreu em adultos, em contexto ocupacional não relacionado ao setor agropecuário e por tentativa de suicídio (OKUYAMA et al., 2020). A área urbana apresenta um alto registro de casos de intoxicação se comparado às áreas rurais e a maioria dos casos ocorrem devido às tentativas de suicídio (HENDGES et al., 2019).

Bochner e Freitas (2020) afirmam que a análise das mortes por intoxicações no Brasil por múltiplos agentes é muito importante para a saúde pública, pois tem como foco a introdução de novas informações que possam subsidiar intervenções específicas de saúde e gerar ações e políticas mais direcionadas. Dessa forma, é importante conhecer esse perfil epidemiológico específico.

Foi observado que entre os agentes de envenenamento, os agrotóxicos estão entre as principais causas de óbitos no Brasil como um todo e também por regiões, além de estarem relacionados com o suicídio (BOCHNER; FREITAS, 2020). Foram estimadas cerca de 14 milhões de mortes prematuras desde 1960, uma vez que as taxas de suicídio por pesticidas aumentaram dramaticamente depois que a Revolução Verde trouxe produtos altamente perigosos para as famílias rurais pobres. Mesmo com aparente queda ao redor do mundo, ainda assim esse tipo de intoxicação é responsável por cerca de 150.000 mortes a cada ano (KARUNARATHNE; AYANTHI et al., 2020).

Há de se considerar que ao contrário da situação de intoxicação aguda, é muito difícil estabelecer a relação causal da intoxicação crônica para as manifestações patológicas que aparecem após meses ou anos de exposição contínua e frequente a agrotóxicos em baixas doses. Um amplo número de marcas comerciais com diferentes princípios eficazes, torna a situação mais complicada e os médicos não estão familiarizados com isso. Nestes casos, os médicos devem contar com os serviços do Centro de Informação Toxicológica (CIT), que podem responder rapidamente à composição química do produto considerado responsável pelo caso, fornece especificações de diagnóstico, desintoxicação e prognóstico (NEVES et al., 2020). 
Quanto ao adoecimento associado ao trabalho agrícola, as mulheres são as mais atingidas pelos transtornos mentais comuns e os homens são os mais vitimados pelo suicídio (NEVES; PIGNATI; PIGNATTI et al., 2020). As intoxicações no sexo feminino podem ocorrer devido à exposição fora do ambiente laboral, no próprio ambiente doméstico, ao entrar em contato com os agentes químicos no momento da lavagem de roupas contaminadas (MIREMA et al., 2017).

Vale ressaltar que os casos de intoxicação por agrotóxicos não se apresentam apenas no setor agrário, mas há um aumento de registros desses casos nos ambientes domiciliares também, em decorrência da utilização das substâncias químicas para comercialização de produtos cosméticos no controle de vetores (QUEIROS et al., 2019), a exemplo do que mostrou a pesquisa de Freitas e Garibaldi (2020), no qual revelou maiores frequências de ocorrência de intoxicação na residência e no ambiente de trabalho.

No setor agrícola os casos identificados têm uma relação com a falta de equipamentos durante manipulação dos mesmos, contudo, no ambiente domiciliar os casos estão mais associados às tentativas de suicídio, já que através da comercialização tem-se uma maior facilidade de acesso a essas substâncias químicas (QUEIROS et al., 2019).

Assim, dentre os agrotóxicos mais utilizados os herbicidas e inseticidas têm o destaque durante a pulverização e a diluição, predispondo os acidentes com o manuseio dos agrotóxicos sem Equipamentos de Proteção Individual (EPI) durante a manipulação. Nos casos de acidentes por uso de agrotóxicos no ambiente domiciliar, eles são ocasionados devido ao armazenamento inadequado, assim como, à reutilização das embalagens (FREITAS; GARIBATTI, 2020)

O aumento do consumo e a aplicação exagerada de agrotóxicos na produção agrícola, a limitação, a falta de fiscalização do uso de proteção individual, a carência de conhecimentos sobre a exposição e os riscos com agrotóxicos levam à ocorrência e ao aumento de doenças por intoxicações, especialmente nos trabalhadores do campo. Esses fatores são considerados um risco para a saúde desses laboriosos e configuram-se como um problema de saúde pública (SILVA; FERREIRA; SILVA et al., 2019).

Os casos de exposições por agrotóxicos estão associados não apenas à falta, como também, ao uso irregular dos EPIs, pois a grande maioria dos trabalhadores não, usam qualquer tipo de proteção por diversas razões. O uso dos EPIs é necessário durante suas atividades de campo e tem o objetivo de diminuir os riscos de intoxicações e acidentes de trabalho (MAGALHÃES; CALDAS, 2019).

Os trabalhadores que estão mais expostos aos agrotóxicos, são os agricultores rurais que trabalham no campo, agente de vigilância ambiental e guarda de endemias que realizam atividades de combate a vetores de doenças no campo. Esses trabalhadores são expostos a produtos agrotóxicos 
diariamente, pois estão envolvidos em suas diversas atividades agropecuárias ou campanhas de saúde pública (MAGALHÃES; CALDAS, 2019). Outros grupos de risco são os pilotos agrícolas e ajudantes (NEVES; MENDONÇA; BELLINI et al., 2020).

Segundo Magalhães e Caldas (2019), as características dos trabalhadores que são expostos a agrotóxicos são do sexo masculino, predominante de 30 a 39 anos com baixa escolaridade e pouco conhecimento sobre a utilização do EPI. Nesse sentido, a exposição aos agrotóxicos pode se dar pela absorção dérmica, como também, pela ingestão e respiração, compondo as principais formas de penetração dos agrotóxicos no corpo humano (BENDOR, 2008).

A forma mais utilizada para aplicação dos agrotóxicos é a pulverização através da manipulação da bomba costal ou também chamado de pulverizador costal. Por ser equipamento versátil, fácil de manusear, é bastante utilizado na produção de diferentes culturas agrícolas e a contaminação dos trabalhadores pode estar relacionada ao processo de calibração e utilização do equipamento, assim como, à realização da higienização do equipamento, pois, normalmente, é feita de modo precário, sem treinamento prévio (ADISSI; PINHEIRO, 2007) ou, com nível baixo de conhecimento quanto ao manejo adequado das etapas de pulverização (CASALI et al., 2015).

Quanto à evolução dos casos, na pesquisa de Ramos e colaboradores (2020) que utilizou os dados do SINAN e SINITOX, revelou que a maioria das intoxicações por agrotóxicos evoluem para a cura, com 48,09\% (SINITOX) e 78,3\% (SINAN). Contudo, há um número relevante de casos que a evolução do caso está como ignorado ou em branco, e, portanto, não há confirmação da cura.

Nesta perspectiva, a avaliação dos casos de intoxicação por agrotóxicos na região Sul do Brasil no período entre 1999 e 2014, com base no estudo de Hendges e colaboradores, realizado através de um banco de dados do Sinitox, foi possível observar que o número de casos de envenenamento é maior para os homens. A faixa etária com a maior ocorrência de intoxicação foi entre 15 e 59 anos (HENDGES et al., 2019).

No período de 2010 a 2015 foram 185 casos de intoxicação por agrotóxicos notificados no Sinan no estado de Alagoas. Após a análise dos resultados, identificou-se um perfil prevalente de agricultores que apresentaram intoxicação por agrotóxicos, sendo ele: sexo masculino, faixa etária entre 35 a 49 anos, escolaridade da I. ${ }^{a}$ à $4 .{ }^{a}$ série, o agente tóxico mais citado foi o agrotóxico agrícola do tipo herbicida, a forma de exposição prevalente foi a pulverização (MAIA et al., 2018). Vale ressaltar, que em todo estado de Alagoas, o município de Igreja Nova, foi o que apresentou o maior número de notificações no período de 2011 a 2015, com um total de 167 casos dentre os 185 de todo estado (MAIA et al., 2018).

Do mesmo modo, ao analisar o perfil epidemiológico dos casos notificados em laboriosos da agricultura, pecuária e serviços conexos, entre 2007 e 2011, no estado da Bahia, encontraram-se 66,2\% 
do sexo masculino, da faixa etária de 20 há 49 anos (63,2\%), de raça/cor parda (69\%) e que possuíam apenas o ensino fundamental (39,5\%). A forma de contaminação prevalente foi a tentativa de suicídio (35,1\%), o agrotóxico mais utilizado foi inseticida (40,1\%) e o local de exposição mais citado foi a residência e o ambiente de trabalho, ambos com 40,1\% (SOUZA et al., 2016). Apesar do alto índice de tentativa de suicídio, a maioria não teve êxito, já que observamos grande número de casos de cura sem sequelas dos pacientes que foram notificados (SOUZA et al., 2016).

Além disso, é importante a realização de ações de prevenção e de atendimentos efetivados por uma equipe de profissionais na área rural junto à unidade de saúde para futuras avaliações da saúde dos trabalhadores rurais, para auxiliar e diminuir os casos de intoxicações por produtos químicos. Sendo assim, facilitando a identificação das intoxicações, realizando um trabalho com assistência e tratamento humanizado a essa população (MAGALHÃES; CALDAS, 2019).

\section{CONCLUSÕES}

A realização dessa revisão sobre as intoxicações associados à exposição aos agrotóxicos na população de trabalhadores revelou que esses agravos acometem principalmente trabalhadores do sexo masculino, perfil socioeconômico com grau de escolaridade e renda baixos e presença de casos tanto na zona urbana como rural. A contaminação acidental por agrotóxico, a pulverização no 53 ambiente de trabalho, a correlação com áreas urbanas que possivelmente ocorre em função das correntes de ar trazidas dos campos, seguido dos acidentes nos ambientes domiciliares são considerados os principais meios das ocorrências de intoxicação.

Percebe-se que os trabalhadores rurais que não fazem uso de EPI ou os utilizam inadequadamente estão mais expostos aos riscos de intoxicação, bem como com a utilização dos pesticidas inadequadamente/indiscriminada. A falta de fiscalização do uso correto dos equipamentos de proteção e desinformação sobre a exposição e os riscos à saúde podem provocar o aumento da ocorrência de doenças, tornando as intoxicações um problema de saúde pública.

Outro ponto de destaque é a falta de experiência por parte dos profissionais de saúde desde a anamnese ao preenchimento adequado das notificações, além da subnotificação, que podem prejudicar as análises, as intervenções específicas em tempo oportuno e a adoção de políticas com abrangência condizentes com a realidade do problema.

É de fundamental importância a oferta de melhores condições de trabalho para os trabalhadores rurais, a criação de legislação para tomar mínimo os riscos que esses trabalhadores estão expostos e a promoção da educação em saúde, com a finalidade de sensibilizar acerca de relevância das medidas preventivas, além de uma assistência adequada. 
Além disso, é necessário a realização de pesquisas futuras acerca da temática, da caracterização dos casos registrados das intoxicações por agrotóxicos e dos fatores predisponentes para a ocorrência das intoxicações, para que sejam propostas medidas preventivas ou corretivas.

\section{REFERÊNCIAS}

ARAÚJO, I. M. M.; OLIVEIRA, Â. G. R. C. Agronegócio e agrotóxicos: impactos à saúde dos trabalhadores agrícolas no nordeste brasileiro. Trabalho, Educação e Saúde, v.I5, n.I, p. II7 - 129, 2017. DOI: https://doi.org/10.1590/1981-7746-solooo43

ADISSI, P. J; PINHEIRO, F. A. Avaliação de risco ocupacional na aplicação manual de agrotóxicos. XXVII Encontro Nacional de Engenharia de Produção. Foz do Iguaçu, PR, Brasil, o9 a il de outubro de 2007.

BOCHNER, R; FREIRE, M. M. Análise dos óbitos decorrentes de intoxicação ocorridos no Brasil de 2010 a 2015 com base no Sistema de Informação sobre Mortalidade (SIM). Ciência \& Saúde Coletiva, v. 25, n. 2, p. 761-772, 2020. DOI: 10.1590/1413-81232020252.15452018

BOCHNER, R. Óbito ocupacional por exposição a agrotóxicos utilizado como evento sentinela: quando pouco significa muito. Vigilância Sanitária em Debate, v. 3, n. 4, p. 39-49, 2015.

CASALI, A. L et al. Nível de capacitação e informação dos operadores de máquinas para a aplicação de agrotóxicos. Ciência Rural, v. 45, n. 3, p. 425 - 431, 2015.

DANTAS, J. S. S et al. Perfil do paciente com intoxicação exógena por "chumbinho" na abordagem inicial em serviço de emergência. Revista Eletrônica de Enfermagem [Internet], v. 15, n. I, p. 54-6o, 2013. https://doi.org/10.5216/ree.visir.15506

FENZKE, M. N et al. Adoecimentos e fatores relacionados à saúde do trabalhador rural. Revista de Enfermagem da UFPE on line, Recife, v.12, n.8, p.2214-26, ago., 2018. DOI: https://doi.org/ro.5205/198I-8963 vi2i8a231532p2214-2226-2018

FREITAS, A. B.; GARIBOTTI, V. Caracterização das notificações de intoxicações exógenas por agrotóxicos no Rio Grande do Sul, 2011-2018. Epidemologia e Serviço de Saúde [preprint]. 2020 [citado 2020 ago 29]: [20 p.]. DOI: https://doi.org/ro.159o/s1679-49742020000500009

GURGEL, A. M. et al. Reflexos da perda do controle estatal sobre os agrotóxicos no Brasil e sua regulação pelo mercado. Reciis-Revista Eletrônica de Comunicação, Informação \& Inovação em Saúde. v. II, n. 3, 2017. https://doi.org/I0.29397/reciis.vi4i4.1923

HENDGES, $C$ et al. Human intoxication by agrochemicals in the region of South Brazil between 1999 and 2014. Journal of Environmental Science and Health, Part B, v. 54, n. 4, p. 219-225, 2019.

KARUNARATHNE, A et al. How many premature deaths from pesticide suicide have occurred since the agricultural Green Revolution? Clinical toxicology, v. 58, n. 4, p. 227-232, 2020.

MAGALHÃES, A. F. A.; CALDAS, E. D. Exposição e intoxicação ocupacional a produtos químicos no Distrito Federal. Revista Brasileira de Enfermagem, Brasília 2019, 72 SUPPL 1:36-44. 
MAIA, J. M. M. M.; LIMA, J. L.; ROCHA, T. J. M.; FONSECA, S. A.; MOUSINHO, K. C.; SANTOS, A. F. Perfil de intoxicação dos agricultores por agrotóxicos em Alagoas. Diversitas Journal. v. 3, n. 2 (mai./ago. 2018), p: 486-504. DOI: 10.17648/diversitas-journal-v3i2.626

MARTINS, M. K. S et al. Exposição ocupacional aos agrotóxicos: um estudo transversal. Revinter. 2012;5(3):6-27.

MELLO, C. M; SILVA L. F. Fatores associados à intoxicação por agrotóxicos: estudo transversal com trabalhadores da cafeicultura no sul de Minas Gerais. Epidemiol. Serv. Saúde. 2013; 22(4):609620.

MENDES, K. D. S.; SILVEIRA, R. C. C. P.; GALVAO, C. M. Utilização do gerente de referência bibliográfica na seleção de estudos primários em revisões integrativas. Texto \& Contexto Enfermagem, Florianópolis, v. 28, e20170204, 2019. https://doi.org/10.1590/1980-265x-tce-2017-0204.

METHLEY, A. M et al. PICO, PICOS and SPIDER: a comparison study of specificity and sensitivity in three search tools for qualitative systematic reviews. BMC Health Serv Res [Internet], v. 14, p. 579, 2014. Disponível em: https://doi.org/Io.1186/s12913-014-0579-o Acesso em: 04 jan. 2020.

MREMA, E. J. Exposição a pesticidas e problemas de saúde entre mulheres trabalhadores de horticultura na Tanzânia. Environmental Health Insights, v. II , p. I-3, 2017.

MURAKAMI, Y et al. Intoxicação crônica por agrotóxicos em fumicultores. Saúde Debate. 2017;4I(II3):563-76.

NEVES, M. S et al. Determinação social do processo saúde-adoecimento mental de trabalhadores rurais no Brasil. ACENO, v. 7, n. I4, p. 231-248, 2020.

NISHIYAMA, P. Utilização de agrotóxicos em áreas de reforma agrária no estado do Paraná. [tese]. Campinas: Universidade Estadual de Campinas; 2003.

OKUYAMA, J. H. H.; GALVAO, T. F.; SILVA, M. T. Intoxicações e fatores associados ao óbito por agrotóxicos: estudo caso controle, Brasil, 2017. Revista Brasileira de Epidemiologia, Rio de Janeiro, v. 23, e200024, 2020. http://dx.doi.org/10.1590/1980-549720200024.

PRESGRAVE, R. F., CAMACHO, L. A. B., VILlAS BOAS, M. H. S. Analysis of data from Poison Control Centers in Rio de Janeiro, Brazil, for use in public health activities. Cadernos de Saúde Pública, v. 25, n. 2, p. 40I-8, 2009. https://doi.org/ro.1590/Soro23iIX2009000200019.

QUEIROZ, P. R et al. Sistema de Informação de Agravos de Notificação e as intoxicações humanas por agrotóxicos no Brasil. Revista Brasileira de Epidemiologia, Rio de Janeiro, v. 22, e190033, 2019. https://doi.org/10.1590/1980-549720190033

RAMOS, M. L. H. et al. Perfil epidemiológico dos casos de intoxicação por agrotóxicos de 2013 a 2017 no Brasil. Brazilian Journal of Development, Curitiba, v. 6, n. 7, p. 43802-43813, 2020. DOI:I0.34117/bjdv6n7 -II9 
SILVA, D. O et al. Exposição aos agrotóxicos e intoxicações agudas em região de intensa produção agrícola em Mato Grosso, 2013. Epidemiologia e Serviços de Saúde, Brasília, v. 28, n. 3, e2018456, 2019. https://doi.org/10.5123/s1679-49742019000300013

SILVA, M.M.; DOMINGUES, S.; BONADIMAN, A. Avaliação de Intoxicação por agrotóxicos e práticas de uso de trabalhadores rurais na Serra Catarinense. Brazilian Journal of Development, v. 5, n. 9, p. 15190-15204, 2019. DOI: 10.34117/bjdv5n9-107

SOUZA C. D. F.; COSTA, K. F.; RAMOS, L. S. Distribuição espacial das intoxicações exógenas por agrotóxicos em trabalhadores rurais no estado da Bahia-Brasil, de 2007 a 2011. Hygeia - Revista Brasileira de Geografia Médica e da Saúde, v. 12, n. 23, p. 133 - 141, Dez/2016. Disponível em: http://www.seer.ufu.br/index.php/hygeia Acesso em I8 jan. 202I.

WHITTEMORE, R et al. Métodos para síntese de conhecimento: uma visão geral. Coração Pulmão, v. 43, n. 5, p. 453-6I, 2014. Disponível em: https://doi.org/ı.1016/j.hrtlng.2014.05.014 Acesso em: II jan. 2021. 